\title{
Epigenetic Changes in Neurodegenerative Diseases
}

\author{
Min Jee Kwon ${ }^{1,4}$, Sunhong Kim ${ }^{2,3,4}$, Myeong Hoon Han ${ }^{1}$, and Sung Bae Lee ${ }^{1, *}$
}

\begin{abstract}
Afflicted neurons in various neurodegenerative diseases generally display diverse and complex pathological features before catastrophic occurrence of massive neuronal loss at the late stages of the diseases. This complex nature of neuronal pathophysiology inevitably implicates systemwide changes in basic cellular activities such as transcriptional controls and signal cascades, and so on, as a cause. Recently, as one of these systemwide cellular changes associated with neurodegenerative diseases, epigenetic changes caused by protein toxicity have begun to be highlighted. Notably, recent advances in related techniques including next-generation sequencing (NGS) and mass spectrometry enable us to monitor changes in the post-translational modifications (PTMs) of histone proteins and to link these changes in histone PTMs to the specific transcriptional changes. Indeed, epigenetic alterations and consequent changes in neuronal transcriptome are now begun to be extensively studied in neurodegenerative diseases including Alzheimer's disease (AD). In this review, we will discuss details of our current understandings on epigenetic changes associated with two representative neurodegenerative diseases $[A D$ and polyglutamine (polyQ) diseases] and further discuss possible future development of pharmaceutical treatment of the diseases through modulating these epigenetic changes.
\end{abstract}

\section{INTRODUCTION}

Neurodegenerative diseases refer to a range of neuronal disabilities accompanied by massive neuronal loss at the late stages of the diseases (Vila and Przedborski, 2003). These neurodegenerative diseases include Alzheimer's disease (AD), Parkinson's disease (PD), Huntington's disease (HD), and Lou Gehrig's disease/Amyotrophic lateral sclerosis (ALS) (Forman et al., 2004). These diseases are often accompanied by accu-

\footnotetext{
${ }^{1}$ Department of Brain \& Cognitive Sciences, DGIST, Daegu 42988, Korea, ${ }^{2}$ Disease Target Structure Research Center, Korea Research Institute of Bioscience and Biotechnology (KRIBB), Daejeon 34141, Korea, ${ }^{3}$ Department of Biomolecular Science, University of Science and Technology, Daejeon 34113, Korea, ${ }^{4}$ These authors contributed equally to this work.

${ }^{*}$ Correspondence: sblee@ dgist.ac.kr
}

Received 5 October, 2016; revised 2 November, 2016; accepted 4 November, 2016; published online 18 November, 2016

Keywords: epigenetic changes, histone, neurodegenerative diseases, post-translational modifications mulation of toxic disease proteins (e.g. amyloid beta in $A D$ and huntingtin in HD) either inside or outside of neurons (Forman et al., 2004). Generally, afflicted neurons by toxic disease proteins in neurodegenerative diseases display a wide spectrum of neuronal phenotypes such as dendrite pathology (Kweon et al., 2016), mitochondrial alterations (Schon and Przedborski, 2011), and defective axonal transport (Fischer et al., 2004; Gunawardena and Goldstein, 2001; Gunawardena et al., 2003; Li et al., 2001; Stokin et al., 2005; Wirths et al., 2006), and so on. The complex nature of neuronal pathophysiology inevitably implicates systemwide changes in basic cellular activities as a cause. One of such systemwide cellular changes associated with many neurodegenerative diseases is thought to be epigenetic changes. In the following sections, we will review what we know about epigenetic changes associated with two representative neurodegenerative diseases, $A D$ and poly $Q$ diseases, and discuss possible pharmaceutical interventions.

Along with the rapid increase of extended life-expectancy, one of the most common forms of dementia, $A D$ is considered as a serious world-wide issue. Only a very limited number of $A D$ patients are familial cases, and the majority of the $A D$ patients are sporadic cases. Unlike AD patients of familial cases involving mutations in amyloid precursor protein (APP), presenilin 1 (PS1), presenilin 2 (PS2), apolipoprotein E (APOE), or their associated genes, it has been suggested that various environmental factors are most likely causes of sporadic $A D$ patients. In general, both of these $A D$ cases share many characteristics: elevated levels of AD-associated amyloid-beta 42 (A 342 ) peptides, accumulation of extracellular amyloid plaques, hyper-phosphorylated tau, and formation of intracellular neurofibrillary tangles (NFTs), serious memory disturbances, and eventual neuronal cell death. Until now, many studies focusing on amyloid plaque and NFT accumulation have been conducted to understand the enigmatic nature of the disease and to develop corresponding therapeutic strategies. However, most of these therapeutic approaches were not effective enough in the clinical trials (Mangialasche et al., 2010), and formation of amyloid plaques and NFTs does not always necessarily correlate with memory disturbance (Snowdon et al., 1997). Therefore, the need for new, novel therapeutic strategies is highly demanded.

PolyQ diseases are inherited neurodegenerative diseases that are caused by expansion of glutamine $(\mathrm{Q})$ repeats in the disease-related proteins. There are nine poly $Q$ diseases including $\mathrm{HD}$ and several types of ataxias. Upon $\mathrm{Q}$ expansion, mutated disease proteins prefer forming protein oligomers/aggregates together with their target proteins in the afflicted neurons and thus sequester/trap these target proteins. It is well known that pathogenic polyQ proteins interact with CBP (Fig. 1) that belongs to a histone acetyltransferase (HAT) family in the nucleus 


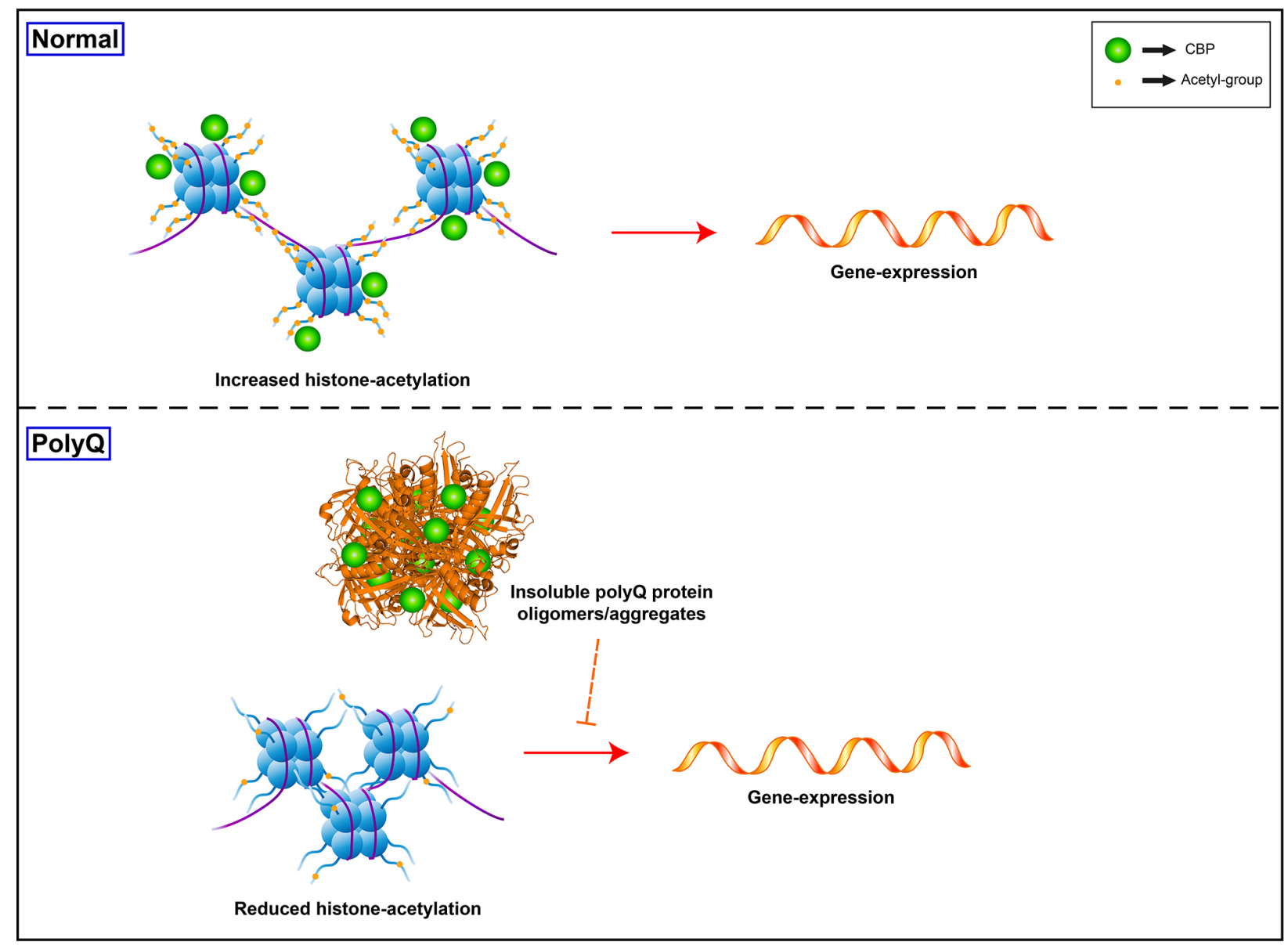

Fig. 1. Decreased levels of histone-acetylation and perturbed regulation of gene-expression resulted by sequestration of CBP in insoluble polyQ protein oligomers/aggregates.

(Nucifora et al., 2001; Steffan et al., 2000). The finding that HAT protein CBP is a well-known target of polyQ proteins encouraged researchers to explore possible epigenetic changes in the polyQ diseases. In particular, HD has been more extensively studied in this regard than other polyQ diseases (Glajch and Sadri-Vakili, 2015).

\section{EPIGENETIC CHANGES AND NEURONAL ABERRATION}

Epigenetic changes refer to alterations in the gene expression without involving any changes in the nucleotide sequence (Egger et al., 2004; Felsenfeld, 2014). Representative epigenetic mechanisms are DNA methylation and histone modifications (Felsenfeld, 2014). Notably, recent advances in next-generation sequencing (NGS) and mass spectrometry have facilitated monitoring any changes in DNA methylation and histone dynamics on the specific gene expression. In this regard, a number of recent studies has successfully implicated epigenetic mechanisms such as DNA methylation and PTMs of histone proteins in complex brain functions such as cognitive function and linked altered epigenome plasticity in many neuronal disorders. Several research groups revealed that lack of proper histone-acetyltransferase (HAT), such as CBP (KAT3A), P300 (KAT3B), and PCAF (KAT2B), activity results in significantly perturbed memory performance (Barrett et al., 2011; Chen et al., 2010; Korzus et al., 2004; Maurice et al., 2008; Oliveira et al., 2007; Oliveira et al., 2011; Wood et al., 2005; 2006).

However, it should be noted that DNA methylation and histone modifications are just not simple enough, and they are tightly controlled by numerous regulator molecules such as DNA methyltransferase (DNMT), a family of HATs, a family of histone deacetylases (HDACs). In addition, there are 4 different core histone proteins ( $\mathrm{H} 2 \mathrm{~A}, \mathrm{H} 2 \mathrm{~B}, \mathrm{H} 3$, and $\mathrm{H} 4)$ that are differently modified at multiple sites, and there are a number of different histone modifications exist: acetylation, methylation, phosphorylation, and ubiquitination (Bannister and Kouzarides, 2011; Strahl and Allis, 2000; Vaquero et al., 2003). Moreover, even for the same type of modifications, their modification pattern can be multiplicated (e.g. 3 different patterns of histone methylation: mono-methylation, di-methylation, and tri-methylation). Because of these, we are now only aware of an association between some representative epigenetic changes and neurodegenerative diseases, which seems to be only a part of the whole picture. Notably, recent advances in the mass spectrometry-based proteomics enable us to better analyze histone PTMs than a conventional approach using site-specific antibodies (Britton et al., 2011). Thus, it is expected that mass spectrometry will immensely contribute in unveiling the exact nature 
of histone modifications in neurodegenerative diseases.

\section{TRANSCRIPTIONAL DYSREGULATION IN NEURODEGENERATIVE DISEASES}

Transcriptional dysregulation has been often associated with neurodegenerative diseases. It has been conceived that transcriptional dysregulation may be, to a certain extent, caused by epigenetic changes in neurodegenerative diseases. The best example of transcriptional dysregulation as a main pathogenic mechanism is $\mathrm{HD}$. One of the critical mechanisms underlying $\mathrm{HD}$ pathogenesis may be transcriptional dysregulation before the onset of massive neuronal cell death mainly observed at the late stages of the diseases (Cha, 2007; Sugars and Rubinsztein, 2003). Supporting this notion, recent studies have successfully demonstrated important contribution of epigenetic mechanisms to this transcriptional dysregulation in HD. According to previous studies, abnormal interactions between pathogenic huntingtin (htt) proteins and several transcription factors, such as nuclear co-repressor (NCoR) (Boutell et al., 1999), RE1-silencing transcription factor/neuron-restrictive silencer factor (REST/NRSF) (Zuccato et al., 2003), and p53 (Steffan et al., 2000), can be one of the key contributing factors for HD pathogenesis. In addition to $\mathrm{HD}$, there is an $\mathrm{AD}$ hypothesis based on transcriptional dysregulation (Robakis, 2003). In line with this, several transcription factors such as Sp1 (Citron et al., 2008) and Egr-1 (Hendrickx et al., 2014; Koldamova et al., 2014) have been implicated to APP-related AD pathogenesis. Moreover, microarray analyses revealed changes in gene expression profiling in AD (Blaclock et al., 2004; Ho et al., 2001). The transcriptional dysregulation is also reported in other types of neurodegenerative diseases. For example, a recent study proposed that DJ-1 associated with PD can regulate the FOXO transcription factor pathway (Hwang et al., 2013).

\section{CHANGES IN DNA METHYLATION IN NEURODEGENERATIVE DISEASES}

Then, which type of epigenetic changes is more responsible for abovementioned transcriptional dysregulation and various neuronal phenotypes in neurodegenerative diseases? Furthermore, is there any common mechanism for this? The answers for these questions remain unclear, and we surmise that the underlying molecular mechanisms might be much complicated. Firstly, as one of representative epigenetic mechanisms, changes in DNA methylation have recently been implicated in $A D$ and HD. Serious alterations in DNA methylation and hydroxymethylation levels [5-methylcytosine $(5 \mathrm{mC})$ and 5-hydroxymethylcytosine (5-hmC), respectively] (Bradley-Whitman and Lovell, 2013; Chouliaras et al., 2013; Condliffe et al., 2014; Coppieters et al., 2014) have been reported by many studies on $A D$. In addition to $A D$, Fraenkel's group revealed hypomethylation of DNA associated with CpG-poor regions due to toxic polyQ proteins in the HD cell culture model ( $\mathrm{Ng}$ et al., 2013). Additionally, it was shown that mutated htt proteins resulted in decreased level of 7-methyl guanine (7-MG) (Thomas et al., 2013). These findings suggest a possibility that changes in DNA methylation by toxic htt proteins may be linked to dysregulated gene expression in HD. A recent study suggested a direct interaction between pathogenic htt proteins and MeCP2 that belongs to methyl-binding domain-containing proteins. Through this binding, pathogenic htt was shown to bind directly to methylated DNA regions (Jaenisch and Bird, 2003). This suggests an additional pathogenic mechanism involving MeCP2 that can contribute to transcriptional dysregulation in HD.

\section{CHANGES IN HISTONE MODIFICATIONS IN NEURODEGENERATIVE DISEASES}

In addition to these changes in DNA methylation, alterations in the protein level of histones and their modification patterns have been suggested to be involved in AD pathogenesis (Bahan-Javan et al., 2014). In this line, the western blotting results of Perry's group showed significantly upregulated levels of nonnuclear form of histone $\mathrm{H} 1$ in the $\mathrm{AD}$-affected brain regions (Bolton et al., 1999). Moreover, aberrant localization of phosphorylated histone $\mathrm{H} 3$ in cytoplasm and their hyperphosphorylation of $\mathrm{H} 3$ were reported in $A D$ hippocampal neurons (Ogawa et al., 2003). Additionally, Arancio's group showed significantly (almost 50\%) decreased levels of hippocampal acetylated histone $4(\mathrm{H} 4)$ in APP/PS1 mice after fear conditioning training (Francis et al., 2009). Notably, a possible involvement of confound regulations of HDACs, whose levels are intimately associated with histone modification levels, in AD pathogenesis has been also implicated by various studies. According to the previous study done in 2012 by Tsai's group, the levels of HDAC2 were significantly increased in the brains of $A D$ patients, and reduced levels of HDAC2 proteins reinstated memory impairment and perturbed synaptic plasticity in amyloid-based AD moue model (Gräff et al., 2012). In addition to HDAC2, substantially increased levels of HDAC6 were observed in AD brains (Ding et al., 2008). Supporting this notion, another study done by Fischer's group revealed that reduction of HDAC6 levels reversed memory deficits presented in the APP/PS1 mouse model (Govindarajan et al., 2013). On the contrary, it appears not all HDACs work in the same manner since another study showed that reduction of HDAC5 (AgisBalboa et al., 2013) levels in APP/PS1 mouse models even worsened the already defective memory phenotypes. However, the roles of other HDAC proteins, such as HDAC1 and HDAC3, in $A D$ pathology are still vague, and more studies are needed. Although the roles of HATs and HDACs on chromatin plasticity and gene-expression have been continuously studied, only several genes were examined and implicated in $A D$ via chromatin-immunoprecipitation (ChIP) technique. Therefore, alterations in chromatin state and their associated mechanistic details are very limited and mostly still remained to be elucidated. In effort to resolve this issue and perform genome-wide analysis, researchers have recently started to apply ChIP-sequencing technique in their studies. In 2014, Feany's group performed large-scale analyses and reported heterochromatin loss in the brains of $A D$ patients that lead to an overall increase in transcription of genes that were normally silenced in normal individuals (Frost et al., 2014). Additionally, Tsai and Kellis's group attempted to profile transcriptional and chromatin state dynamics and found downregulation of synaptic plasticity genes and upregulation of immune response genes (Gjoneska et al., 2015). Taken together, histone alterations associated with $A D$ are summarized in Fig. 2.

In addition, several studies have reported that pathogenic htt caused a global reduction of histone acetylation (Chiu et al., 2011; Ferrante et al., 2003; Gardian et al., 2005; Giralt et al., 2012; Igarashi et al., 2003; Jiang et al., 2006; Lim et al, 2011; Stack et al., 2007). On the other hand, other groups did not observe the equivalent phenomenon even using the same model systems (Hockly et al., 2003; Klevytska et al., 2010; Oliveira et al., 2006; Sadri-Vakili et al., 2007). Thus, the reduction of histone acetylation by pathogenic htt still remains contro- 


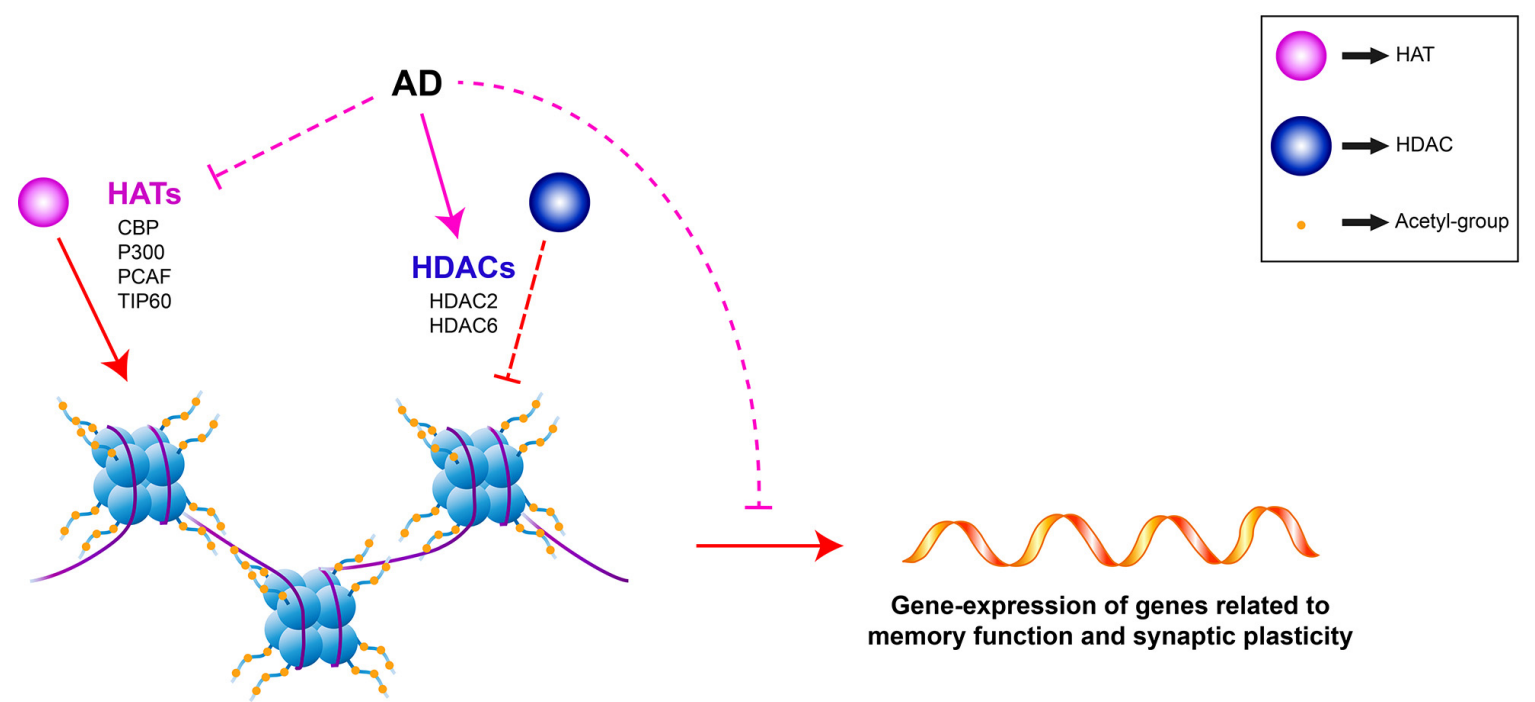

Histone-acetylation

Fig. 2. Possible involvements of HATs and HDACs in controlling gene-expression of genes associated with memory function and synaptic plasticity in $A D$.

versial. Nonetheless, the involvement of CBP in HD pathogenesis is strongly supported by accumulated evidences (Fig. 1). Amongst various HATs, it seems likely that CBP plays a crucial role in HD pathogenesis. Although the sequestration of CBP in intracellular htt inclusions has been well reported (McCampbell et al., 2000), one of HATs that shares prominent similarity to CBP, p300, may not be affected by pathogenic htt (Cong et al., 2005). Moreover, overexpression of p300 failed to ameliorate the toxicity caused by pathogenic htt proteins unlike in the case of CBP (Nucifora et al., 2001). In addition to HAT, a number of studies using genetic approach have assessed the role of HDACs in HD models. In a C. elegans HD model, htt toxicity was substantially suppressed when the levels of HDAC3 ortholog was decreased (Bates et al., 2006). Also in a Drosophila HD model, decreasing levels of specific HDACs such as Rpd3 and Sir2 was shown to repress htt toxicity in the afflicted neurons (Pallos et al., 2008). However, Bates group reported that in the R6/2 mouse model of HD, genetic knock-down of HDAC3 (Moumne et al., 2012), HDAC6 (Bobrowska et al., 2011), or Sirt2 (Bobrowska et al., 2012) failed to suppress the pathological phenotypes. Therefore, additional studies in mouse models with various genetic backgrounds should be done in order to gain much clearer understanding on the role of epigenetic controls in disease pathogenesis.

\section{LIMITATIONS, CHALLENGES, AND FUTURE DIRECTION OF USING EPIGENETIC DRUGS FOR NEURODEGENERATIVE DISEASES}

The idea of using epigenetic drugs to ameliorate neurodegenerative diseases has been already tested in various model animal studies. Previous studies have shown that the memory defects shown in various $A D$ models were significantly reversed with the use of various histone-deacetyltransferase (HDAC) inhibitors: sodium butyrate, suberoylanilide hydroxamic acid (SAHA, Vorinostat), trichostatin A (TSA), or valproate (VPA) (Fischer et al., 2007; Francis et al., 2009; Kilgore et al., 2010).
Besides restoration of memory function and synaptic plasticity, oral administration of HDAC inhibitor MS-275 (Entinostat) substantially decreased neuroinflammation and amyloid plaque accumulation observed in APP/PS1 AD models (Zhang and Schluesener, 2013). Surprisingly, sodium butyrate treatment was effective even when it was administrated at the late stage of the disease progression, after the onset of neuronal cell death (Govindarajan et al., 2011). In addition, a number of studies have shown a similar therapeutic role of HDAC inhibitors in PD and HD models (Coppedè, 2010; Sadri-Vakili and Cha, 2006).

The methylation of DNA and histone proteins requires Sadenosyl methionine (SAM) as a methyl donor, and the level of SAM seems to be reduced in AD patients (Coppedè, 2010). Several studies in mice showed that the deficiency of vitamin B, which is required for synthesis of SAM, led to hypomethylation of PSEN1 promoters, and subsequent deposition of $A \beta$ (Coppedè, 2010). In line with these results, there are some evidences suggesting that vitamin $B$ supplement can reduce the cognitive defects in various $A D$ model mice and patients, although further investigation is still required (Coppedè, 2010).

One of the most critical points about using these HDAC inhibitors is that multiple HDAC proteins (among four classes of 11 HDAC proteins) are affected at the same time. Due to this simultaneous influence on a broad spectrum of HDAC proteins, it is not clear which one of them is primarily responsible and most appropriate therapeutic target for AD-induced memory perturbation or HD-induced locomotive defects in minimizing potential side effects. Despite their effectiveness, it is yet uncertain that these epigenetic-based therapeutic approaches, including HDAC inhibitors, can change or modify disease pathology itself. Also, it remains unclear whether the changes in histoneacetylation in $A D$ and $H D$ are crucial cause of disease pathogenesis or just mere consequence of diseases itself.

\section{CONCLUSION}

In this article, we reviewed pathological implication of epigenetic 
changes associated with two representative neurodegenerative diseases and discussed possible application of pharmaceutical modulation of these epigenetic changes as a disease treatment. Toxic disease proteins associated with $A D$ and poly $Q$ diseases can modify PTMs of histones and subsequent transcriptional control of many genes, which may ultimately lead to diverse and complex neuronal phenotypes. As reviewed here, with the help of recent advance in the related techniques such as NGS and mass spectrometry, we are now able to recognize some of key mediators and roughly figure out the working mechanisms of these epigenetic changes. However, epigenetic dysregulation is not only specifically limited to two neurodegenerative diseases we discussed above, $A D$ and $H D$, but also prevalently reported in other neurodegenerative diseases including PD and ALS. With tremendous efforts of the researchers in this field assisted by great advances in technology, it is expected that the exact nature of epigenetic changes in theses neurodegenerative diseases will be unveiled in the near future, which then will practically contribute to the development of effective treatment of the diseases.

\section{ACKNOWLEDGMENTS}

This work was supported by the DGIST R\&D and MIREBraiN program, Basic Science Research Program through the ministry of science, ICT \& future planning of Korea (16-BD-0402, 2013R1A1A1004978), and the Development of Platform Technology for Innovative Medical Measurements Program from the Korea Research Institute of Standards and Science (KRISS2016-16011064) (S.B.L.).

\section{REFERENCES}

Agis-Balboa, R.C., Pavelka, Z., Kerimoglu, C., and Fischer, A. (2013). Loss of HDAC5 impairs memory function: implications for Alzheimer's disease. J. Alzheimers. Dis. 33, 35-44.

Bahari-Javan, S., Sananbenesi, F., and Fischer, A. (2014). Histoneacetylation: a link between Alzheimer's disease and posttraumatic stress disorder? Front. Neurosci. 8, 160.

Bannister, A.J., and Kouzarides, T. (2011). Regulation of chromatin by histone modifications. Cell Res. 21, 381-395

Barrett, R.M., Malvaez, M., Kramar, E., Matheos, D.P., Arrizon, A., Cabrera, S.M., Lynch, G., Greene, R.W., and Wood, M.A. (2011) Hippocampal focal knockout of CBP affects specific histone modifications, long-term potentiation, and long-term memory. Neuropsychopharmacology 36, 1545-1556.

Bates, E.A., Victor, M., Jones, A.K., Shi, Y., and Hart, A.C. (2006). Differential contributions of Caenorhabditis elegans histone deacetylases to huntingtin polyglutamine toxicity. J. Neurosci. 26, 2830-2838.

Blalock, E.M., Geddes, J.W., Chen, K.C., Porter, N.M., Markesbery, W.R., and Landfield, P.W. (2004). Incipient Alzheimer's disease: microarray correlation analyses reveal major transcriptional and tumor suppressor responses. Proc. Natl. Acad. Sci. USA 101, 2173-2178.

Bobrowska, A., Paganetti, P., Matthias, P., and Bates, G.P. (2011). Hdac6 knock-out increases tubulin acetylation but does not modify disease progression in the $R 6 / 2$ mouse model of Huntington's disease. PLoS One 6, e20696.

Bobrowska, A., Donmez, G., Weiss, A., Guarente, L., and Bates, G. (2012). SIRT2 ablation has no effect on tubulin acetylation in brain, cholesterol biosynthesis or the progression of Huntington's disease phenotypes in vivo. PLoS One 7, e34805.

Bolton, S.J., Russelakis-Carneiro, M., Betmouni, S., and Perry, V.H. (1999). Non-nuclear histone $\mathrm{H}_{1}$ is upregulated in neurones and astrocytes in prion and Alzheimer's diseases but not in acute neurodegeneration. Neuropathol. Appl. Neurobiol. 25, 425-432.

Boutell, J.M., Thomas, P., Neal, J.W., Weston, V.J., Duce, J., Harper, P.S., and Jones, A.L. (1999). Aberrant interactions of transcriptional repressor proteins with the Huntington's disease gene product, huntingtin. Hum. Mol. Genet. 8, 1647-1655.
Bradley-Whitman, M.A., and Lovell, M.A. (2013). Epigenetic changes in the progression of Alzheimer's disease. Mech. Ageing. Dev. 134, 486-495.

Britton, L.M., Gonzales-Cope, M., Zee, B.M., and Garcia, B.A. (2011). Breaking the histone code with quantitative mass spectrometry. Expert. Rev. Proteomics. 8, 631-643.

Cha, J.H. (2007). Transcriptional signatures in Huntington's disease. Prog. Neurobiol. 83, 228-248.

Chen, G., Zou, X., Watanabe, H., van Deursen, J.M., and Shen, J. (2010). CREB binding protein is required for both short-term and long-term memory formation. J. Neurosci. 30, 13066-13077.

Chiu, C.T., Liu, G., Leeds, P., and Chuang, D.M. (2011). Combined treatment with the mood stabilizers lithium and valproate produces multiple beneficial effects in transgenic mouse models of Huntington's disease. Neuropsychopharmacology 36, 24062421.

Chouliaras, L., Mastroeni, D., Delvaux, E., Grover, A., Kenis, G., Hof, P.R., Steinbusch, H.W., Coleman, P.D., Rutten, B.P., and van den Hove, D.L. (2013). Consistent decrease in global DNA methylation and hydroxymethylation in the hippocampus of Alzheimer's disease patients. Neurobiol. Aging 34, 2091-2099.

Citron, B.A., Dennis, J.S., Zeitlin, R.S., and Echeverria, V. (2008). Transcription factor Sp1 dysregulation in Alzheimer's disease. J. Neurosci. Res. 86, 2499-2504.

Condliffe, D., Wong, A., Troakes, C., Proitsi, P., Patel, Y., Chouliaras, L., Fernandes, C., Cooper, J., Lovestone, S., Schalkwyk, L., et al. (2014). Cross-region reduction in 5hydroxymethylcytosine in Alzheimer's disease brain. Neurobiol. Aging 35, 1850-1854.

Cong, S.Y., Pepers, B.A., Evert, B.O., Rubinsztein, D.C., Roos, R.A., van Ommen, G.J., and Dorsman, J.C. (2005). Mutant huntingtin represses CBP, but not p300, by binding and protein degradation. Mol, Cell Neurosci. 30, 560-571.

Coppedè, F. (2010). One-carbon metabolism and Alzheimer's disease: focus on epigenetics. Curr. Genomics 11, 246-260.

Coppieters, N., Dieriks, B.V., Lill, C., Faull, R.L., Curtis, M.A., and Dragunow, M. (2014). Global changes in DNA methylation and hydroxymethylation in Alzheimer's disease human brain. Neurobiol. Aging 35, 1334-1344.

Ding, H., Dolan, P.J., and Johnson, G.V. (2008). Histone deacetylase 6 interacts with the microtubule-associated protein tau. J. Neurochem. 106, 2119-2130.

Egger, G., Liang, G., Aparicio, A., and Jones, P.A. (2004). Epigenetics in human disease and prospects for epigenetic therapy. Nature 429, 457-463.

Felsenfeld, G. (2014). A brief history of epigenetics. Cold Spring Harb Perspect. Biol. 6, a018200.

Ferrante, R.J., Kubilus, J.K., Lee, J., Ryu, H., Beesen, A., Zucker, B., Smith, K., Kowall, N.W., Ratan, R.R., Luthi-Carter, R., et al. (2003). Histone deacetylase inhibition by sodium butyrate chemotherapy ameliorates the neurodegenerative phenotype in Huntington's disease mice. J. Neurosci. 23, 9418-9427.

Fischer, L.R., Culver, D.G., Tennant, P., Davis, A.A., Wang, M. Castellano-Sanchez, A., Khan, J., Polak, M.A., and Glass, J.D. (2004). Amyotrophic lateral sclerosis is a distal axonopathy: evidence in mice and man. Exp. Neurol. 185, 232-240.

Fischer, A., Sananbenesi, F., Wang, X., Dobbin, M., and Tsai, L.H. (2007). Recovery of learning and memory after neuronal loss is associated with chromatin remodeling. Nature 447, 178-182.

Forman, M.S., Trojanowski, J.Q., and Lee, V.M. (2004) Neurodegenerative diseases: a decade of discoveries paves the way for therapeutic breakthroughs. Nat. Med. 10, 1055-1063.

Francis, Y.I., Fà, M., Ashraf, H., Zhang, H., Staniszewski, A., Latchman, D.S., and Arancio, O. (2009). Dysregulation of histone acetylation in the APP/PS1 mouse model of Alzheimer's disease. J. Alzheimers Dis. 18, 131-139.

Frost, B., Hemberg, M., Lewis, J., and Feany, M.B. (2014). Tau promotes neurodegeneration through global chromatin relaxation Nat. Neurosci. 17, 357-366.

Gardian, G., Browne, S.E., Choi, D.K., Klivenyi, P., Gregorio, J., Kubilus, J.K., Ryu, H., Langley, B., Ratan, R.R., Ferrante, R.J., et al. (2005). Neuroprotective effects of phenylbutyrate in the N171$82 \mathrm{Q}$ transgenic mouse model of Huntington's disease. J. Biol. Chem. 280, 556-563.

Giralt, A., Puigdellivol, M., Carreton, O., Paoletti, P., Valero, J., Parra-Damas, A., Saura, C.A., Alberch, J., and Gines, S. (2012). 
Long-term memory deficits in Huntington's disease are associated with reduced CBP histone acetylase activity. Hum. Mol. Genet. 21, 1203-1216.

Gjoneska, E., Pfenning, A.R., Mathys, H., Quon, G., Kundaje, A., Tsai, L.H., and Kellis, M. (2015). Conserved epigenomic signals in mice and humans reveal immune basis of Alzheimer's disease. Nature 518, 365-369.

Glajch, K.E., and Sadri-Vakili, G. (2015). Epigenetic mechanisms involved in huntington's disease pathogenesis. J. Huntingtons Dis. 4, 1-15.

Govindarajan, N., Agis-Balboa, C., Walter, J., Sananbenesi, F., and Fischer, A. (2011). Sodium butyrate improves memory function in an Alzheimer's disease mouse model when administered at an advanced stage of disease progression. J. Alzheimers Dis. 26, 187-197.

Govindarajan, N., Rao, P., Burkhardt, S., Sananbenesi, F., Schlüter, O.M., Bradke, F., Lu, J., and Fischer, A. (2013). Reducing HDAC6 ameliorates cognitive deficits in a mouse model for Alzheimer's disease. EMBO Mol. Med. 5, 52-63.

Gräff, J., Rei, D., Guan, J.S., Wang, W.Y., Seo, J., Hennig, K.M., Nieland, T.J., Fass, D.M., Kao, P.F., Kahn, M., et al. (2012). An epigenetic blockade of cognitive functions in the neurodegenerating brain. Nature 483, 222-226.

Gunawardena, S., and Goldstein, L.S. (2001). Disruption of axonal transport and neuronal viability by amyloid precursor protein mutations in Drosophila. Neuron 32, 389-401.

Gunawardena, S., Her, L.S., Brusch, R.G., Laymon, R.A., Niesman, I.R., Gordesky-Gold, B., Sintasath, L., Bonini, N.M., and Goldstein, L.S. (2003). Disruption of axonal transport by loss of huntingtin or expression of pathogenic polyQ proteins in Drosophila. Neuron 40, 25-40.

Hendrickx, A., Pierrot, N., Tasiaux, B., Schakman, O., KienlenCampard, P., De Smet, C., and Octave, J.N. (2014). Epigenetic regulations of immediate early genes expression involved in memory formation by the amyloidprecursor protein of Alzheimer disease. PLoS One 9, e99467.

Ho, L., Guo, Y., Spielman, L., Petrescu, O., Haroutunian, V., Purohit, D., Czernik, A., Yemul, S., Aisen, P.S., Mohs, R., et al. (2001). Altered expression of a-type but not b-type synapsin isoform in the brain of patients at high risk for Alzheimer's disease assessed by DNA microarray technique. Neurosci. Lett. 298, 191-194.

Hockly, E., Richon, V.M., Woodman, B., Smith, D.L., Zhou, X., Rosa, E., Sathasivam, K., Ghazi-Noori, S., Mahal, A., Lowden, P.A., et al. (2003). Suberoylanilide hydroxamic acid, a histone deacetylase inhibitor, ameliorates motor deficits in a mouse model of Huntington's disease. Proc. Natl. Acad. Sci. USA 100, 2041-2046.

Hwang, S., Song, S., Hong, Y.K., Choi, G., Suh, Y.S., Han, S.Y., Lee, M., Park, S.H., Lee, J.H., Lee, S., et al. (2013). Drosophila DJ-1 decreases neural sensitivity to stress by negatively regulating Daxx-like protein through dFOXO. PLoS Genet. 9, e1003412.

Igarashi, S., Morita, H., Bennett, K.M., Tanaka, Y., Engelender, S., Peters, M.F., Cooper, J.K., Wood, J.D., Sawa, A., and Ross, C.A (2003). Inducible PC12 cell model of Huntington's disease shows toxicity and decreased histone acetylation. Neuroreport $14,565-$ 568.

Jaenisch, R., and Bird, A. (2003). Epigenetic regulation of gene expression: How the genome integrates intrinsic and environmental signals. Nat. Genet. 33, 245-254.

Jiang, H., Poirier, M.A., Liang, Y., Pei, Z., Weiskittel, C.E., Smith, W.W., DeFranco, D.B., and Ross, C.A. (2006). Depletion of CBP is directly linked with cellular toxicity caused by mutant huntingtin. Neurobiol. Dis. 23, 543-551.

Kilgore, M., Miller, C.A., Fass, D.M., Hennig, K.M., Haggarty, S.J., Sweatt, J.D., and Rumbaugh, G. (2010). Inhibitors of class 1 histone deacetylases reverse contextual memory deficits in a mouse model of Alzheimer's disease. Neuropsychopharmacology $35,870-880$

Klevytska, A.M., Tebbenkamp, A.T., Savonenko, A.V., and Borchelt, D.R. (2010). Partial depletion of CREB-binding protein reduces life expectancy in a mouse model of Huntington disease. J. Neuropathol. Exp. Neurol. 69, 396-404.

Koldamova, R., Schug, J., Lefterova, M., Cronican, A.A., Fitz, N.F., Davenport, F.A., Carter, A., Castranio, E.L., and Lefterov, I. (2014). Genome-wide approaches reveal EGR1-controlled regulatory networks associated with neurodegeneration. Neurobiol Dis. 63, 107-114.

Korzus, E., Rosenfeld, M.G., and Mayford, M. (2004). CBP histone acetyltransferase activity is a critical component of memory consolidation. Neuron 42, 961-972.

Kweon, J.H., Kim, S., and Lee, S.B. (2016). The cellular basis of dendrite pathology in neurodegenerative diseases. BMB Rep. [Epub ahead of print]

Li, H., Li, S.H., Yu, Z.X., Shelbourne, P., and Li, X.J. (2001). Huntingtin aggregate-associated axonal degeneration is an early pathological event in Huntington's disease mice. J. Neurosci. 21 , 8473-8481.

Lim, S., Chesser, A.S., Grima, J.C., Rappold, P.M., Blum, D., Przedborski, S., and Tieu, K. (2011). D-beta-hydroxybutyrate is protective in mouse models of Huntington's disease. PLoS One 6, e24620.

McCampbell, A., Taylor, J.P., Taye, A.A., Robitschek, J., Li, M., Walcott, J., Merry, D., Chai, Y., Paulson, H., Sobue, G., et al. (2000). CREB-binding protein sequestration by expanded polyglutamine. Hum. Mol. Genet. 9, 2197-2202.

Mangialasche, F., Solomon, A., Winblad, B., Mecocci, P., and Kivipelto, M. (2010). Alzheimer's disease: clinical trials and drug development. Lancet Neurol. 9, 702-716.

Maurice, T., Duclot, F., Meunier, J., Naert, G., Givalois, L., Meffre, J. Célérier, A., Jacquet, C., Copois, V., Mechti, N., et al. (2008) Altered memory capacities and response to stress in p300/CBP. associated factor (PCAF) histone acetylase knockout mice. Neuropsychopharmacology 33, 1584-1602.

Moumne, L., Campbell, K., Howland, D., Ouyang, Y., and Bates, G.P. (2012). Genetic knock-down of HDAC3 does not modify disease related phenotypes in a mouse model of Huntington's disease. PLoS One 7, e31080.

Ng, C.W., Yildirim, F., Yap, Y.S., Dalin, S., Matthews, B.J., Velez, P.J., Labadorf, A., Housman, D.E., and Fraenkel, E. (2013) Extensive changes in DNA methylation are associated with expression of mutant huntingtin. Proc. Natl. Acad. Sci. USA 110, 2354-2359.

Nucifora, F.C., Jr., Sasaki, M., Peters, M.F., Huang, H., Cooper J.K., Yamada, M., Takahashi, H., Tsuji, S., Troncoso, J., Dawson, V.L., et al. (2001). Interference by huntingtin and atrophin-1 with cbp-mediated transcription leading to cellular toxicity. Science 291, 2423-2428.

Ogawa, O., Zhu, X., Lee, H.G., Raina, A., Obrenovich, M.E., Bowser, R., Ghanbari, H.A., Castellani, R.J., Perry, G., and Smith, M.A. (2003). Ectopic localization of phosphorylated histone H3 in Alzheimer's disease: a mitotic catastrophe? Acta. Neuropathol. 105, 524-528.

Oliveira, J.M., Chen, S., Almeida, S., Riley, R., Goncalves, J., Oliveira, C.R., Hayden, M.R., Nicholls, D.G., Ellerby, L.M., and Rego, A.C. (2006). Mitochondrial-dependent $\mathrm{Ca}^{2+}$ handling in Huntington's disease striatal cells: Effect of histone deacetylase inhibitors. J. Neurosci. 26, 11174-11186.

Oliveira, A.M., Wood, M.A., McDonough, C.B., and Abel, T. (2007). Transgenic mice expressing an inhibitory truncated form of p300 exhibit long-term memory deficits. Learn. Mem. 14, 564-572.

Oliveira, A.M., Estévez, M.A., Hawk, J.D., Grimes, S., Brindle, P.K., and Abel, T. (2011). Subregion-specific p300 conditional knockout mice exhibit long-term memory impairments. Learn. Mem. 18 161-169.

Pallos, J., Bodai, L., Lukacsovich, T., Purcell, J.M., Steffan, J.S., Thompson, L.M., and Marsh, J.L. (2008). Inhibition of specific HDACs and sirtuins suppresses pathogenesis in a Drosophila model of Huntington's disease. Hum. Mol. Genet. 17, 3767-3775.

Robakis, N.K. (2003). An Alzheimer's disease hypothesis based on transcriptional dysregulation. Amyloid 10, 80-85.

Sadri-Vakili, G., and Cha, J.H. (2006). Mechanisms of disease: Histone modifications in Huntington's disease. Nat. Clin. Pract. Neurol. 2, 330-338.

Sadri-Vakili, G., Bouzou, B., Benn, C.L., Kim, M.O., Chawla, P., Overland, R.P., Glajch, K.E., Xia, E., Qiu, Z., Hersch, S.M., et al. (2007). Histones associated with downregulated genes are hypoacetylated in Huntington's disease models. Hum. Mol. Genet. 16, 1293-1306.

Schon, E.A., and Przedborski, S. (2011). Mitochondria: the next (neurode)generation. Neuron 70, 1033-1053.

Snowdon, D.A., Greiner, L.H., Mortimer, J.A., Riley, K.P., Greiner, 
P.A., and Markesbery, W.R. (1997). Brain infarction and the clinical expression of Alzheimer's disease. The Nun Study. JAMA 277, 813-817.

Stack, E.C., Del Signore, S.J., Luthi-Carter, R., Soh, B.Y., Goldstein, D.R., Matson, S., Goodrich, S., Markey, A.L., Cormier, K., Hagerty, S.W., et al. (2007). Modulation of nucleosome dynamics in Huntington's disease. Hum. Mol. Genet. 16, 1164-1175.

Steffan, J.S., Kazantsev, A., Spasic-Boskovic, O., Greenwald, M. Zhu, Y.Z., Gohler, H., Wanker, E.E., Bates, G.P., Housman, D.E., and Thompson, L.M. (2000). The Huntington's disease protein interacts with p53 and CREB-binding protein and represses transcription. Proc. Natl. Acad. Sci. USA 97, 6763-6768.

Stokin, G.B., Lillo, B., Falzone, T.L., Brusch, R.G., Rockenstein, E., Mount, S.L., Raman, R., Davies, P., Masliah, E., Williams, D.S., et al. (2005). Axonopathy and transport deficits early in the pathogenesis of Alzheimer's diseases. Science 307, 1282-1288.

Strahl, B.D., and Allis, C.D. (2000). The language of covalent histone modifications. Nature 403, 41-45.

Sugars, K.L., and Rubinsztein, D.C. (2003). Transcriptional abnormalities in Huntington disease. Trends. Genet. 19, 233-238.

Thomas, B., Matson, S., Chopra, V., Sun, L., Sharma, S., Hersch,

S., Rosas, H.D., Scherzer, C., Ferrante, R., and Matson, W. (2013). A novel method for detecting 7-methyl guanine reveals aberrant methylation levels in Huntington disease. Anal. Biochem. 436, 112-120.

Vaquero, A., Loyola, A., and Reinberg, D. (2003). The constantly changing face of chromatin. Sci. Aging Knowledge Environ. 2003, RE4.

Vila, M., and Przedborski, S. (2003). Targeting programmed cell death in neurodegenerative diseases. Nat. Rev. Neurosci. 4, 365-375.

Wirths, O., Weis, J., Szczygielski, J., Multhaup, G., and Bayer, T.A. (2006). Axonopathy in an APP/PS1 transgenic mouse model of Alzheimer's disease. Acta. Neuropathol. 111, 312-319.

Wood, M.A., Kaplan, M.P., Park, A., Blanchard, E.J., Oliveira, A.M., Lombardi, T.L., and Abel, T. (2005). Transgenic mice expressing a truncated form of CREB-binding protein (CBP) exhibit deficits in hippocampal synaptic plasticity and memory storage. Learn. Mem. 12, 111-119.

Wood, M.A., Attner, M.A., Oliveira, A.M., Brindle, P.K., and Abel, T. (2006). A transcription factor-binding domain of the coactivator $\mathrm{CBP}$ is essential for long-term memory and the expression of specific target genes. Learn. Mem. 13, 609-617.

Zhang, Z.Y., and Schluesener, H.J. (2013). Oral administration of histone deacetylase inhibitor MS-275 ameliorates neuroinflammation and cerebral amyloidosis and improves behavior in a mouse model. J. Neuropathol. Exp. Neurol. 72, 178-185.

Zuccato, C., Tartari, M., Crotti, A., Goffredo, D., Valenza, M., Conti, L., Cataudella, T., Leavitt, B.R., Hayden, M.R., Timmusk, T., et al. (2003). Huntingtin interacts with REST/NRSF to modulate the transcription of NRSE-controlled neuronal genes. Nat. Genet. 35, 76-83. 